\title{
REESTRUTURAÇÃO URBANA DA FRANJA LITORÂNEA DA VIA COSTEIRA, NATAL/RN.
}

\author{
Tatiana Francischini Brandão dos Reis ${ }^{1}$
}

\author{
Ruth Maria da Costa Ataíde ${ }^{2}$
}

\begin{abstract}
RESUMO
A cidade de Natal apresenta uma grande diversidade de ecossistemas marinhos e terrestres que, em sintonia (ou não) com os espaços construídos, configuram uma paisagem litorânea peculiar e exuberante, bastante atrativa para os setores turístico e imobiliário. No entanto, essas belezas naturais encontram-se ameaçadas e, em alguns casos, em risco de degradação, devido à ocupação inadequada das suas franjas litorâneas, especialmente da orla marítima. Apesar do potencial cênico e da grande reserva de espaços livres, a cidade carece, ainda, de espaços públicos de lazer, com adequado planejamento que assegura a proteção de suas reservas naturais. Nesse contexto o artigo tem por objetivo apresentar uma proposta de reestruturação urbana para a Via Costeira e seu entorno, visando a dinamização dos seus espaços livres, através da instalação de atividades e equipamentos de interesse público e privado. Para tanto, foram realizados estudos de caracterização físico-ambiental da franja litorânea, localizada em uma das margens da Via e delimitada como ZET-2, e do seu entorno imediato, que resultaram na definição dos condicionantes e das diretrizes projetuais para uma proposta de reestruturação urbana, em nível de macrozoneamento, aqui apresentada.
\end{abstract}

PALAVRAS-CHAVE: Via costeira. Orla marítima de Natal. Espaços livres públicos.

\section{RESTRUCTURING THE URBAN FRINGE OF COASTAL ROUTE COAST, NATAL/RN.}

\author{
ABSTRACT \\ The city of Natal has a very diverse both marine and terrestrial ecosystems that, in line (or not) with \\ the built spaces, constitute a unique and exuberant coastal landscape, very attractive for tourism and \\ real estate sectors. However, those natural beauty and ecosystems are threatened and, in some \\ cases at risk of degradation due to the disorderly occupation of the coasts, especially the seafront.

\footnotetext{
${ }^{1}$ Arquiteta e Urbanista, aluna especial do programa de pós-graduação em Arquitetura e Urbanismo (mestrado). tatyfranci@hotmail.com.

${ }^{2}$ Arquiteta e Urbanista, Dr ${ }^{\mathrm{a}}$ em Pensamiento Geografico y Organización del Territorio pela Universidade de Barcelona, professora e pesquisadora de graduação e do programa de pósgraduação em Arquitetura e Urbanismo da UFRN. rataide_58@hotmail.com.
} 


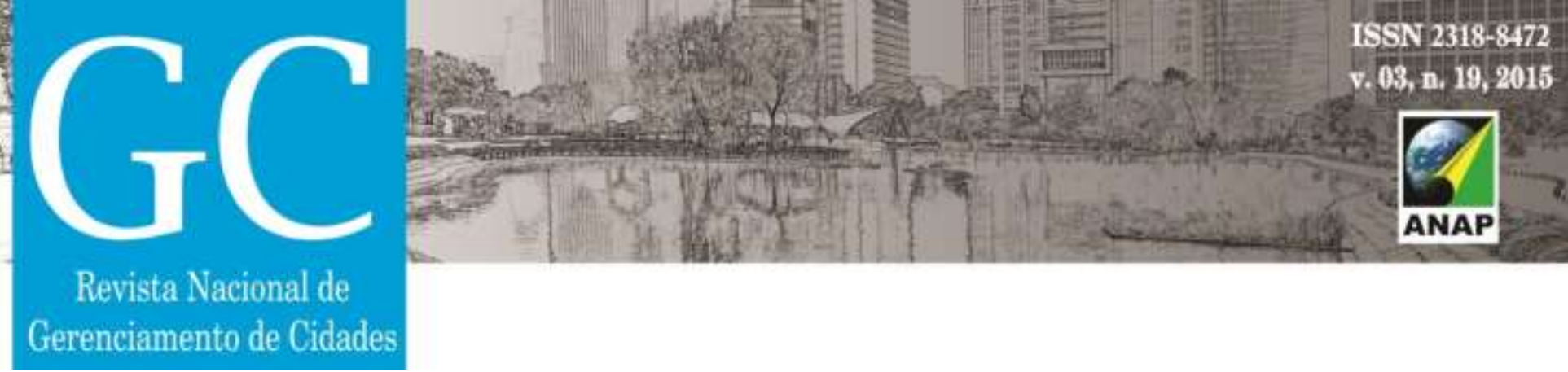

Despite its scenic potential and large reserves of open spaces, the city of Natal lacks, though, public leisure spaces, sports and culture with proper planning and preservation of its natural resources. As a result this paper aims to present a proposal for urban restructuring to the Via Costeira and its surroundings, with aimint to improve its open spaces, through leasing activities and public and private equipment. Therefore, studies were conducted to characterize the physical environment through the ZET-2 and its immediate surroundings and the proposed urban conditions, which resulted in the definition of general and specific guidelines as well as the proposed restructuring at the level of macrozoning, herein presented.

KEYWORDS: Via Costeira, Seafront of Natal. Open Spaces.

\section{REESTRUCTURACIÓN DE LA FRANJA COSTERA RUTA URBANA COSTA, NATAL/RN.}

\section{RESUMEN}

La ciudad de "Natal" presenta una gran diversidad de ecosistemas marinos y terrestres que, en sintonía (o no) con los espacios construidos, diseñan un paisaje peculiar y exuberante, muy atractivo a los sectores turístico e inmobiliario. Sin embargo, estas bellezas naturales están amenazadas y, en algunos casos, en riesgo de degradación, debido a la ocupación incorrecta de sus franjas costeras, especialmente de la costa. A pesar del potencial escénico y de la grande reserva de espacios libres, la ciudad necesita aún, de espacios públicos de ocio, deporte y cultura con una planificación adecuada que garantice la protección de sus recursos naturales. En este contexto, el artículo pretende presentar una propuesta de reestructuración urbana de la Vía Costera y sus alrededores, con el objetivo de la promoción del uso de sus espacios libres, mediante la instalación de equipos y actividades de interés público y privado. Para ello, se realizaron estudios de caracterización físico ambiental de la franja costera, ubicada en uno de los bordes de la vía y delimitada como ZET-2 y su entorno inmediato, que resultó en la definición de las condiciones y de las directrices de proyecto para una propuesta de reestructuración urbana, a nivel de microzonificación, presentada en este artículo.

PALAVRAS-CLAVE: Via Costeira, Franjas Costeras de Natal. Espacios Libres. 
Revista Nacional de

Gerenciamento de Cidades

\section{INTRODUÇÃO}

O presente artigo $^{3}$ se insere no contexto de discussão sobre o controle do uso e da ocupação do solo de zonas costeiras, em especial da orla marítima, visto que nesse espaço ambientalmente vulnerável materializam-se conflitos socioambientais e disputas entre os diferentes agentes sociais pela sua apropriação. Nesse contexto, afirma-se que "os espaços praiais devem ser objeto prioritário das ações de ordenamento e regulamentação” (BRASíLIA, 2006, p.27), considerando que a orla, além de ser a área mais cobiçada por setores econômicos, apresenta ecossistemas diversos e formações fisiográficas frágeis do ponto de vista ambiental.

Nessa perspectiva, com este artigo, apresentamos uma proposta de restruturação e gestão dos espaços livres existentes na Via Costeira, Natal/RN, considerando a fragilidade ambiental dessa fração urbana e o seu valor patrimonialnatural e paisagístico para a cidade de Natal. Para isso, foram definidos 3 eixos de intervenção, que compreendem terrenos passíveis de intervenção situados na orla (glebas livres), acessos públicos à praia e eixo viário da Via Costeira (RN - 301).

Assim, em um primeiro momento abordamos os eixos estruturantes que norteiam as diretrizes gerais aplicadas à proposta como um todo - considerando os três eixos de intervenção anteriormente definidos.

Dessa forma, realizou-se a análise físico-ambiental de cada um dos eixos, de modo a evidenciar suas potencialidades e limitações desde o ponto de vista urbanístico ao ambiental para que a partir disso, fosse desenvolvida a proposta de macrozoneamento - resultado final do artigo.

O artigo está estruturado em 4 partes principais : área de intervenção: a via costeira no contexto municipal; antecedentes históricos e aspectos normativos; a construção da proposta; e o macrozoneamento, conforme será visto na sequência.

\footnotetext{
${ }^{3}$ Este artigo configura-se como um desdobramento do trabalho final de graduação apresentado em dezembro de 2014 e intitulado "Via Costeira sempre viva: uma proposta de reestruturação da ZET-2 e seu entorno".
} 
Revista Nacional de

Gerenciamento de Cidades

\section{2. ÁREA DE INTERVENÇÃO: A VIA COSTEIRA NO CONTEXTO MUNICIPAL}

A fração urbana aqui estudada corresponde à Via Costeira ${ }^{4}$ e seu entorno ${ }^{5}$ localizada no município de Natal, capital do estado do Rio Grande do Norte, Brasil. Esta fração, de acordo com o Plano Diretor (NATAL, 2007), não integra nenhuma das quatro regiões administrativas da cidade e delimita-se pelos bairros de Mãe Luiza e Areia Preta (ao Norte) e Ponta Negra (ao Sul). À Leste e à Oeste, delimita-se por espaços protegidos tais como a faixa de praia ${ }^{6}$, o Parque das Dunas ${ }^{7}$ e as áreas definidas como Zona de Proteção Ambiental 10 (ZPA10) e Área Especial de Interesse Social de Mãe Luiza (AEIS de Mãe Luiza). Portanto, os espaços livres presentes na faixa litorânea da Via Costeira, delimitada como Zona Especial de Interesse Turístico-2 (ZET-2), somados à própria via, enquanto eixo viário constitui a área de proposta do macrozoneamento, conforme delimitado na figura 1.

É importante ressaltar, ainda, que a Via Costeira configura-se como elemento estruturante da articulação entre as regiões Norte/Leste e Sul da Região Metropolitana de Natal - sendo considerada uma via essencial na conexão física entre os destinos turísticos da RMNatal, uma vez que esta se articula com os litorais norte e sul do estado através da ponte Newton Navarro e da rota do sol, respectivamente.

Outro aspecto relevante, no que concerne à sua localização e articulação com o restante da cidade consiste no fato desta área ser delimitada: de um lado pelo mar do outro pelo Parque da Dunas - que se revela uma barreira física natural de crescimento, impedindo uma maior integração desta área com o restante do tecido

\footnotetext{
${ }_{5}^{4}$ A Via Costeira é denominada Avenida Senador Dinarte Mariz e RN-301, rodovia estadual.

${ }^{5}$ No contexto deste estudo o entorno da Via Costeira a ser estudado abrange a área definida como Zona Especial e Interesse Turístico-2 (ZET-2), entre a própria via e a praia.

${ }^{6}$ Segundo inciso art.9 $9^{\circ}$, inciso I, da lei no 7.871/00 (RIO GRANDE DO NORTE, 2000), que dispõe sobre o Zoneamento Ecológico-Econômico do Litoral Oriental do Rio Grande do Norte, as praias são Áreas de Preservação (APs), portanto espaços protegidos.

7 O Parque das Dunas é criado pelo Decreto $n^{\circ} 7.237 / 77$ (RIO GRANDE DO NORTE, 1977) e posteriormente regulamentado pelo Decreto estadual oํ 7538/79 (RIO GRANDE DO NORTE, 1979).
} 


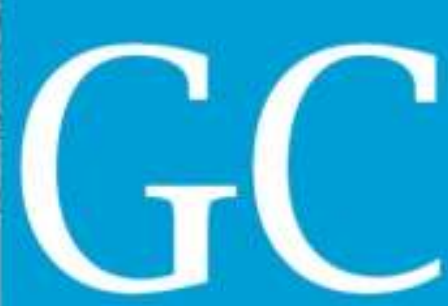

Revista Nacional de

Gerenciamento de Cidades

urbano. Tal fato, dentre outros fatores ${ }^{8}$, explica a fraca dinâmica, apropriação e relação dessa área com o restante da cidade (Figura 1).

\section{Figura 1 - Caracterização da área de estudo}

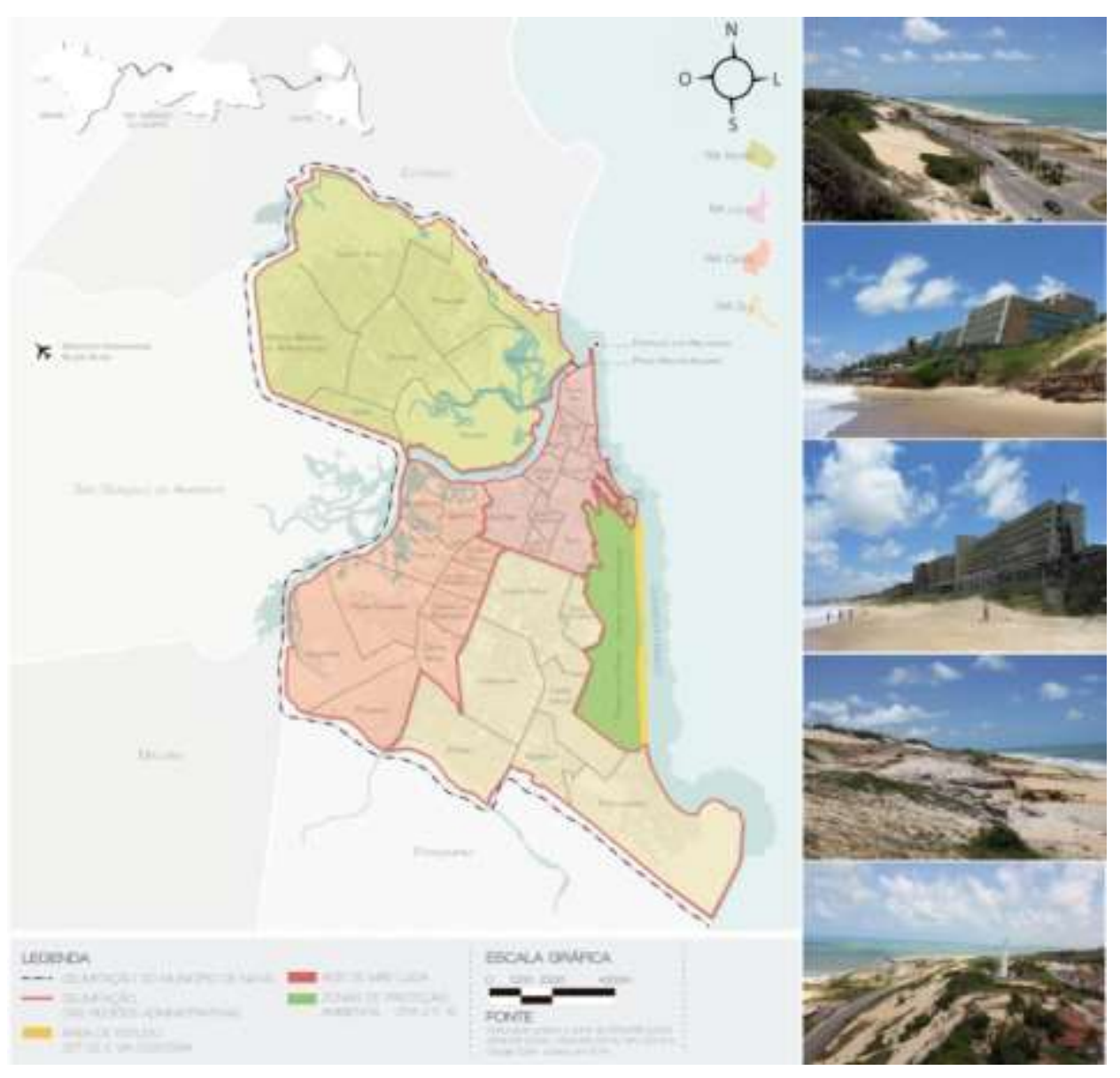

Fonte: REIS, 2014.

\section{ANTECEDENTES HISTÓRICOS E ASPECTOS NORMATIVOS}

O projeto Parque das Dunas/Via Costeira, elaborado pelo escritório paranaense Luiz Forte Netto e posteriormente complementado pelo escritório do

\footnotetext{
${ }^{8}$ Além da Via Costeira ser isolada do ponto de vista da sua integração física com a cidade, ainda não se mostra um espaço convidativo para a prática de atividades pela população de Natal, uma vez que não apresenta equipamentos de lazer, prática de esportes nem infraestrutura para o seu usufruto.
} 
Revista Nacional de

Gerenciamento de Cidades

paisagista Burle Marx ${ }^{9}$, fez parte de uma estratégia política de âmbito estadual, com o propósito de impulsionar o turismo norte-rio-grandense, dotando de infraestrutura hoteleira parte do litoral, em especial o da capital ${ }^{10}$.

Para a sua execução foram necessários diversos trâmites legais, tendo em vista que a área proposta para o projeto incorporava terrenos de marinha ${ }^{11}$ e outros terrenos da União onde hoje se encontram o Parque das Dunas e as glebas concedidas aos investidores do ramo hoteleiro - que foram desapropriadas a partir do decreto estadual $n^{\circ} 7.717 / 79$ (RIO GRANDE DO NORTE, 1979) que declara de utilidade pública, para fins de desapropriação, bens situados na orla marítima entre as praias de Areia Preta e de Ponta Negra.

Este projeto propunha inicialmente, a construção de uma via localizada às margens do cordão dunar das atuais ZPA 2 e ZPA 10 - que interligaria, margeando à orla, o bairro de Ponta Negra à Areia Preta, ou seja, a região central da cidade à zona sul, que estava em processo de ocupação naquele período ${ }^{12}$. Além da construção da Via, o referido projeto apoiava-se em outros 3 pilares: a urbanização da favela da Mãe Luiza, a construção de um parque hoteleiro e a proteção normativa da área do Parque das Dunas conforme observado em declaração oficial do então governador do estado, Tarcísio Maia, a respeito dos objetivos desse projeto:
a) proteger os sistemas geológicos e geomorfológicos das dunas;
b) conter a ocupação desordenada e predatória da área;
c) impedir o crescimento da favela (bairro de Mãe Luiza) e ao mesmo tempo, promover a melhoria de suas condições de urbanização;
d) obter um melhor aproveitamento do potencial turístico e de lazer da faixa litorânea;

\footnotetext{
${ }^{9}$ Devido à forte pressão social, liderada por estudantes, ecólogos e demais representações sociais em defesa da natureza, o estado do RN contratou, em 1979, o escritório de Burle Marx para a elaboração de um projeto paisagístico para a Via Costeira, que previa tanto a arborização do Parque das Dunas quanto o ajardinamento de áreas previstas no macrozoneamento do projeto, na atual ZET2. passaram a incorporar objetivos direcionados ao turismo internacional.

${ }_{11}$ Os terrenos de marinha existentes na área $-419.000 \mathrm{~m}^{2}$ - foram concedidos ao Estado do RN sob regime de aforamento a partir do contrato de cessão instaurado no dia 06/02/79 pelo DSPU local.

12 Segundo ATAÍDE (2013), a ocupação dos bairros de Ponta Negra e da Vila de Ponta Negra já estava em processo consolidação em 1960 e 1970, respectivamente (ATAÍDE, 2013, p.313-314).
} 
e) promover a interligação litorânea de Natal, Dunas e Ponta Negra (KELSON DE OLIVEIRA SILVA, 2010).

A partir disso, o projeto Parque das Dunas/Via Costeira (PDV) foi pensado para ser desenvolvido em etapas, tendo como marco inicial a criação do Parque das Dunas (1977), seguido da construção da via (inaugurada em 1981) e da implementação do complexo hoteleiro, iniciada em 1984 com a construção do Natal Mar Hotel, localizado na primeira parcela da via - no sentido Ponta Negra - Centro.

Infelizmente, a urbanização do bairro de Mãe Luiza, os acessos à praia propostos por Burle Marx, bem como a construção dos equipamentos de lazer $e$ esporte previstos - nunca foram realizados - o que evidencia duas situações: por um lado a preocupação do paisagista em prover a área com espaços públicos estruturados e convidativos para que a população se apropriasse destes, e por outro, o histórico de descaso dos gestores com o cumprimento do projeto inicial, negando a possibilidade de democratização do acesso e uso dos mesmos.

O acesso à praia, espaço público por excelência, previsto por legislação federal ${ }^{13}$ e estadual ${ }^{14}$ também não foi garantido à totalidade da população, visto que apenas os hóspedes dos hotéis têm acessos à praia pela RN-301. Apesar disso, existem acessos informais à praia, utilizados por parte da população. Neste quase 40 anos desde a construção da Via Costeira, houve poucas intervenções ${ }^{15}$ na área, sendo a última reforma responsável pela duplicação da via, supressão do canteiro arborizado e da única ciclovia ${ }^{16}$ existente na cidade.

\footnotetext{
${ }^{13}$ Segundo a Constituição Federal (BRASIL, 1988) cabe ao poder público municipal a garantia do livre e acesso à praia, através do seu Plano Diretor e de outros instrumentos de ordenamento do uso e da ocupação do solo em todo o seu território municipal, de forma articulada às demais esferas de governo.

${ }_{14}$ A Lei n 7942/01 (RIO GRANDE DO NORTE, 2001) cria 13 acessos à praia na Via Costeira.

${ }^{15}$ As intervenções propostas e implementadas na área desde a criação da Via Costeira, bem como o detalhamento das informações e mapas sobre a sua configuração espacial da Via Costeira e entorno estão descritas no trabalho original intitulado "Via Costeira sempre viva: uma proposta de reestruturação urbana para a ZET-2 e seu entorno" (REIS, 2014).

${ }^{16} \mathrm{~A}$ última intervenção realizada na área (2008-2010) criou uma ciclofaixa junto à calçada.
} 


\section{A CONSTRUÇÃO DA PROPOSTA}

Tendo em vista os estudos realizados acerca da configuração espacial da área, especialmente dos eixos de intervenção e a constatação do seu distanciamento da situação de proteção e apropriação desejadas, propõe-se, nessa seção do artigo, a definição de um conjunto de diretrizes gerais e específicas que fundamentam a proposta de reestruturação em curso. Nessa perspectiva, a construção das diretrizes se fundamentou nos seguintes eixos estruturantes:

- As recomendações decorrentes do "Relatório conjunto de avaliação técnica ambiental dos lotes da Via Costeira no Município do Natal/RN" (NATAL, 2010), que considera os terrenos livres presentes na ZET-2 como APPs $^{17}$;

- O projeto paisagístico de Burle Marx (1981) para as áreas livres ainda não ocupadas;

- Os novos usos $^{18}$ e apropriações atribuídos aos espaços livres pela população - públicos e privados - existentes na área de estudo;

- A necessidade de tratamento das áreas de borda dos espaços protegidos $^{19}$

\footnotetext{
17 Segundo RESOLUÇÃO CONAMA n 369/06 que "Dispõe sobre os casos excepcionais, de utilidade pública, interesse social ou baixo impacto ambiental, que possibilitam a intervenção ou supressão de vegetação em Área de Preservação Permanente-APP" em seu Art. 8 e $\S 2^{\circ}$ "Projeto técnico que deverá ser objeto de aprovação pela autoridade ambiental competente, poderá incluir a implantação de equipamentos públicos, tais como: a) trilhas eco turísticas; b) ciclovias; c) pequenos parques de lazer, excluídos parques temáticos ou similares; d) acesso e travessia aos corpos de agua; e) mirantes; f ) equipamentos de segurança, lazer, cultura e esporte; g) bancos, sanitários, chuveiros e bebedouros públicos; e h) rampas de lançamento de barcos e pequenos ancoradouros" (BRASIL, 2006).

${ }^{18}$ Parte da população utiliza alguns terrenos livres existentes na Via Costeira para prática de atividades físicas e de lazer e para aceder à praia - através de caminhos informais.

${ }^{19}$ Considerando que "O tratamento das bordas das ZPAs com projetos urbanísticos e paisagísticos, assim como através do planejamento, com a criação de zonas de amortecimento no entorno daquelas mais vulneráveis apresenta-se como mecanismo que fortalece a preservação e o uso sustentável dessas áreas, realçando as suas fragilidades e, sobretudo, garantindo o direito de todos à sua contemplação e usufruto, a exemplo ZPAs situadas na orla marítima". (SILVA et al., 2012, p.131)
} 
8) Criar novas alternativas de hospedagem e incentivo ao turismo na área;

9) Favorece a permeabilidade e acessibilidade no tecido urbano consolidado de modo a permitir o acesso livre à praia ao longo da Via Costeira;

A partir dessas diretrizes, adiciona-se uma classificação dos terrenos (setorização), acompanhada de prescrições urbanísticas adicionais e complementares às já estabelecidas pela ZET-2, levando em consideração os seguintes condicionantes, especificados na sequência.

Primeiramente, no que se refere à setorização, a proposta orienta-se pelos seguintes condicionantes: a locação dos equipamentos na área deve considerar, dentre outros fatores, o contexto de inserção da gleba e sua relação com o entorno imediato, a proximidade com comunidades e possíveis usuários, o suporte às atividades consolidas na área e, por fim, como dito anteriormente, a vocação de cada terreno de incorporar determinados usos de maneira sustentável, com o menor prejuízo ambiental possível para estes espaços.

Como resultado, identificamos sete setores na área de estudo classificados a partir da sua localização no contexto da Via Costeira e da consideração das suas respectivas características físico-ambientais (Figura 2).

Somada a essa primeira setorização, também foi percebida a necessidade de se considerar a especificação de algumas prescrições urbanísticas adicionais para a área - considerando que cada uma das 16 glebas livres apresenta características físico-ambientais (solo, vegetação e topografia) distintas e, consequentemente, vocações igualmente diferentes quanto à sua ocupação. Nessa perspectiva propõe-se reforçar que o gabarito máximo das edificações esteja de acordo com as prescrições já estabelecidas pelo Plano Diretor de Natal (2007), em seu parágrafo $2^{\circ}$ do artigo 21 :

Os empreendimentos propostos para as áreas situadas na ZET-2 não poderão possuir gabarito máximo que ultrapasse o nível da Avenida Dinarte Mariz; ressalvadas as Áreas em que a localização e as características topográficas do terreno já impeçam a visualização da paisagem, ficando 
nesses casos limitado em 7,5m (sete metros e meio) o gabarito máximo das construções (NATAL, 2007).

Além disso, recomenda-se o remembramento de lotes para a execução de propostas integradas ${ }^{20} \mathrm{em}$ cada um dos setores estabelecidos. Em relação aos recuos, devem ser mantidas as delimitações propostas pela Lei Complementar $n^{\circ}$ 030/00 (NATAL, 2000) posteriormente, reafirmadas na última revisão do Plano Diretor de Natal (2004-2007), com exceção daquele previsto para o lado da via que define 5 e 10 metros de recuo, uma vez que se tem o interesse de instalar equipamentos junto ao limite do terreno. Sendo assim, na proposta, os fundos dos terrenos não apresentam recuo - o que possibilita a criação de mirantes ${ }^{21}$ na laje de cobertura dessas edificações, junto ao passeio de pedestre.

Por fim, foram delimitadas 2 categorias de proteção para as glebas existentes, as quais se materializam em duas subzonas: subzona de preservação e subzona de uso restrito, cujas permissividades quanto ao uso e ocupação do solo são distintas conforme apresentamos a seguir. A subzona de preservação compreende áreas que, devido as suas fragilidades ambientais decorrentes de processos erosivos e da presença cobertura vegetal nativa na maior parte do terreno, não podem ser ocupadas nem acessadas pela população. Nesta zona não é permitido nenhum tipo de uso. Enquadra-se nesse padrão a gleba 17 - maior parcela existente na área definida como ZET-2.

A subzona de uso restrito compreende todos os terrenos que, apesar das suas fragilidades ambientais, podem ser ocupados de maneira sustentável respeitando as demais prescrições urbanísticas anteriormente definidas e as recomendações presentes no relatório do "Relatório conjunto de avaliação técnica ambiental dos lotes da Via Costeira no Município do Natal/RN" (NATAL, 2010). Fazem parte deste grupo 15 das 16 glebas livres analisadas.

\footnotetext{
${ }^{20}$ No caso de se propor um parque linear, por exemplo, é possível o remembramentos de lotes.

${ }^{21} \mathrm{O}$ corte esquemático BB', que exemplifica o mirante, encontra-se na figura 3 , na sequência do artigo.
} 


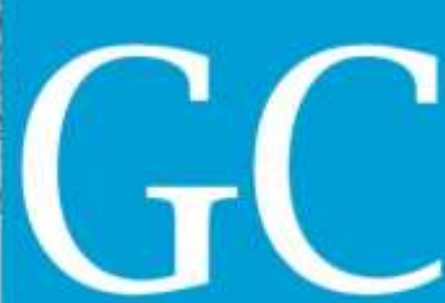

Revista Nacional de

Gerenciamento de Cidades

\section{Figura 2 - Setorização}

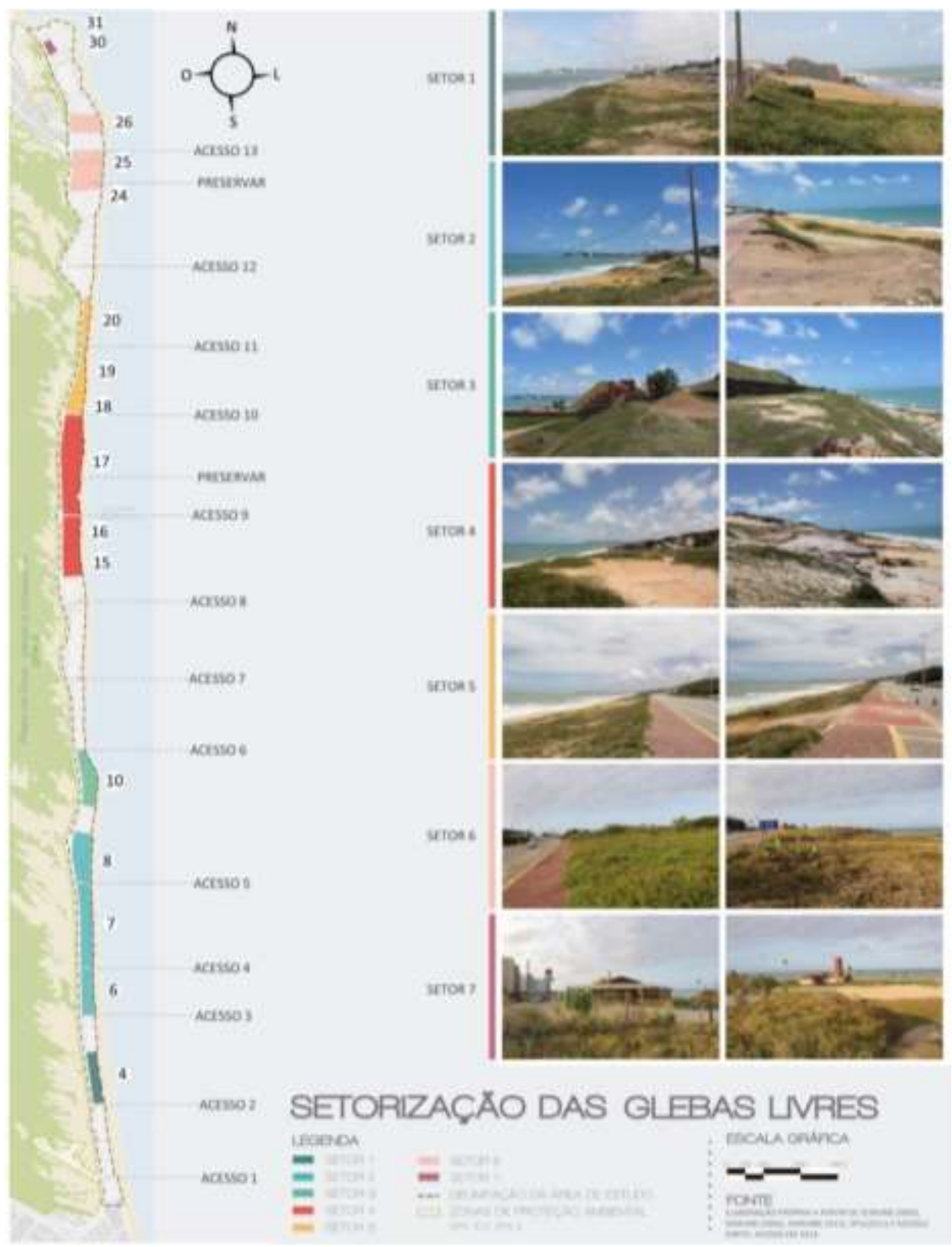

Fonte: Elaboração própria a partir de REIS, 2014.

\section{O MACROZONEAMENTO}

Ainda, considerando as diretrizes apontadas, as características de cada gleba e a respectiva pré-setorização, foi definido o macrozoneamento, como base 


\section{Revista Nacional de}

para a proposta de reestruturação urbanística, a qual divide a área estudada em nove setores e está apresentada em dois eixos de intervenção: os espaços privados (glebas) e públicos (Via Costeira e acessos públicos à praia). Para os espaços privados, delimitados pelas glebas, tomou-se como referência principal a présetorização, resultado do agrupamento das suas características tipológicas, desde a perspectiva físico-ambiental. A esta adicionou-se um novo agrupamento de glebas do setor 6 (glebas 15,16,17), que foi dividido em dois setores 6 e 7, correspondente às glebas 15 e 16 e 17, respectivamente. Para os espaços públicos propõe-se a criação de um novo setor de no 9, que corresponde aos passeios para pedestres, ciclovia, canteiro e leito carroçável. A incorporação e integração dos acessos públicos às glebas reflete uma das diretrizes da proposta.

Quanto aos níveis de proteção, conforme abordado na seção anterior do artigo, adotou-se para as 16 glebas livres, as prescrições contidas no capítulo 1 - Do macrozoneamento do Plano Diretor de Natal (2007), com adaptações. Assim, as 16 glebas livres dividem-se em duas subzonas: de preservação e uso restrito, sendo a gleba de $\mathrm{n}^{\circ} 17$ considerada de preservação e as 15 restantes, de uso restrito.

Quanto às atividades e usos, para todos os setores, com exceção do $n^{\circ} 9$, propõe-se a locação de equipamentos de lazer, cultura e esporte, áreas de convívio social arborizadas, hortos com vegetação nativa, acessos públicos à praia, áreas de camping, piquenique e equipamentos de iniciativa privada que darão suporte ao desenvolvimento das atividades propostas, tais como restaurantes, bares, cafés, lanchonetes e quiosques. A partir dessa sistematização propõe-se a inserção dessas recomendações no macrozoneamento, que está estruturado em nove setores. Para estes propõe-se, a modo de exemplo, um conjunto de atividades e equipamentos nos termos especificados a seguir:

O setor 5: Corresponde à gleba 17 (maior parcela livre da Via Costeira), localizada entre as glebas livres 16 e 18. Esta é marcada pela baixa ação antrópica e, consequente, preservação de suas características geológicas e bióticas Apesar disso, essa área apresenta processos de erosão do solo e a formação de falésias - 


\section{Revista Nacional de}

o que dificultaria a sua ocupação. Sendo assim, tendo em vista suas fragilidades ambientais decorrentes, principalmente, dos processos erosivos lá presentes, bem como pela composição do solo, o perfil topográfico e a presença de vegetação abundante, sugere-se que este setor não apresente nenhum tipo de uso e ocupação, constituindo-se como uma área de proteção integral no nível de preservação.

O setor 6: Correspondendo a fusão das glebas 18, 19 e 20 este setor, envolve terrenos de propriedade da DATANORTE ${ }^{22}$. Nele, sugere-se a criação de um parque linear que incorpore a proposta de Burle Marx para a antiga zona de Belvedere prevista no projeto Parque das Dunas/Via Costeira. Além disso, para as demais áreas livres não contempladas por este projeto - como parte da gleba $19 \mathrm{e}$ totalidade da gleba 20 - propõe-se a realização de passeios arborizados, instalação de mesas para piqueniques e decks de madeira na faixa de terrenos de marinhacom escadarias e rampas de acesso à praia. Os acessos públicos à praia existentes neste setor (10 e 11) serão incorporados ao parque de modo a atender as diretrizes projetuais.

O setor 7: Localizado entre dois hotéis, corresponde à fusão das glebas 24 , 25 e 26 e o espaço público existente, atualmente utilizado pela população do bairro Mãe Luiza (AEIS), tanto para aceder à praia como para a prática de futebol de areia. Propõe-se neste a criação de um parque onde se desenvolvam atividades de educação ambiental (horto com vegetação nativa), lazer (parques infantis e áreas de convivência arborizadas), cultura (anfiteatro ao ar livre, espaço para feiras) e esporte (consolidação da quadra de futebol de areia), tendo em vista a sua proximidade com o bairro de Mãe Luiza, onde há poucos espaços públicos qualificados.

Neste setor também devem ser instalados equipamentos de suporte ao desenvolvimento das atividades acima detalhadas, tais como sanitários, vestiários, quiosques de lanche e pequenas lanchonetes. Além disso, propõe-se a preservação

${ }_{22}^{22}$ De propriedade do estado do Rio Grande do Norte. 


\section{CONSIDERAÇÕES FINAIS}

Definido o macrozoneamento e as indicações das prescrições urbanísticas e das atividades que podem ser instaladas, julga-se necessário considerar a aplicação de mecanismos de gestão que sejam compatíveis com o contexto urbanístico e ambiental da área, de modo a assegurar e garantir a efetividade da proposta. Nesse sentido, destaca-se a necessidade de conciliar, no que couber, os mecanismos de controle do uso e da ocupação do solo, assim como os instrumentos de gestão previstos no Estatuto da Cidade (BRASIL, 2001) e no Plano Diretor de Natal (NATAL, 2007), com as orientações do Projeto Orla (BRASIL, 2006) e do Plano Nacional de Gerenciamento Costeiro II (BRASIL,1997).

Entre esses instrumentos, sugere-se, por exemplo, o estabelecimento de parcerias público-privadas (PPP) para a efetivação da instalação das atividades previstas para os setores de números, $1,2,3,4,5,6,7,8$, de modo a garantir, também, a exploração econômica desses espaços em consonância com o interesse público que fundamenta a proposta, e reduzir os conflitos gerados ${ }^{23}$ com os atuais titulares das concessões dos terrenos.

Aliado a isso, ressalta-se ainda a importância do diálogo entre as legislações urbana e ambiental e a consideração das especificidades dos espaços ambientalmente sensíveis e protegidos inseridos em contextos urbanos. Isto porque se acredita que apropriação e o uso controlado de espaços protegidos por parte da população mostram-se ferramentas de gestão e proteção eficientes, considerando que, quando a população estabelece relações de uso e vivencia estes espaços, ela cria um sentimento de pertencimento, zelo e cuidado com ele e, consequentemente, reivindica a sua proteção.

Assim, pode-se que concluir que a proposta aqui apresentada mostra-se um possível caminho a ser percorrido para que a gestão sustentável desse espaço seja

\footnotetext{
${ }^{23}$ É importante frisar que todas as 5 leis estaduais que alteram ou reformulam o projeto Parque das Dunas/Via Costeira, estabelecem prazos para a construção e início de funcionamento dos equipamentos turísticos previsto para as áreas concedidas. Estes prazos, entretanto, já se esgotaram, cabendo ao estado do Rio Grande do Norte a retomada desses terrenos.
} 
Revista Nacional de

Gerenciamento de Cidades

efetivada. Acredita-se, portanto, que a conversão dos espaços privados inseridos na área definida como ZET-2 em espaços públicos qualificados e estruturados a partir da locação de equipamentos que estimulem a sua apropriação, configura-se como uma garantia de cristalização, proteção e não ocupação desses espaços a longo prazo.

\section{REFERÊNCIAS BIBLIOGRÁFICAS}

ATAIDE, R. M. C.. Interés ambiental frente a interés social: La gestión de los conflictos socioespaciales en los espacios naturales protegidos: los retos de la regularización urbanística de los asentamientos informales en Natal, RN. Tese (Doutorado em Pensiamento Geografico y Organization del Territorio) - Universidade de Barcelona, Barcelona, 2013.

BRASIL. Constituição da República Federativa do Brasil. Brasília: Senado Federal, 1988.

providências. Brasília: DOU, 1988.

. Resolução CONAMA no 369/2006. Dispõe sobre os casos excepcionais, de utilidade pública, interesse social ou baixo impacto ambiental, que possibilitam a intervenção ou supressão de vegetação em Área de Preservação Permanente. Brasília: Ministério do Meio Ambiente, 2006.

GEHL, Jan. Cidades para Pessoas. São Paulo: Perspectiva, 2013.

MACEDO, S. S. ;CUSTODIO, V. ; CAMPOS, A. C. A. ; QUEIROGA, E. F. . Sistemas de espaços livres e forma urbana: algumas reflexões. In: XV ENANPUR - Encontro Nacional da Associação Nacional de Pesquisa e Pós-Graduação em Planejamento Urbano e Regional, 2013, Recife. XV ENANPUR. Recife : ANPUR / UFPE, 2013. v. 1. p. 1-16.

NATAL. Prefeitura Municipal do. Lei Complementar no 082, de 21 de junho de 2007. Dispõe sobre $o$ Plano Diretor de Natal e dá outras providências. Natal, DOMNatal, 2007.

Prefeitura Municipal do. Relatório Conjunto de Avaliação Técnica Ambiental dos Lotes da Via Costeira no Município do Natal/RN. Realizado a partir Portaria Conjunta no 01/2009/PU/SPU/IBAMA. Natal, 2010.

PROJETO ORLA: Fundamentos para Gestão Integrada/ Ministério do Meio Ambiente, Ministério do Planejamento, Orçamento e Gestão. - Brasília: MMA: 2006.

REIS, Tatiana Francischini Brandão dos. Via Costeira sempre viva: uma proposta de reestruturação urbana para ZET-2 e seu entorno. Natal, RN: Monografia (Graduação) - Graduação em Arquitetura e Urbanismo, Universidade Federal do Rio Grande do Norte, 2014. 


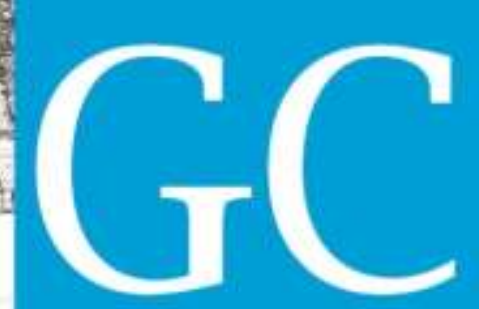

RIO GRANDE DO NORTE. Governo do Estado do. Decreto no 7.538/1979. Aprova o regulamento do Parque das Dunas. Este decreto refere-se à área Parque das Dunas/Via Costeira. Natal: DOE/RN, 1979.

Governo do Estado do. Decreto no 7.942/2001. Reformula o Projeto "Parque das Dunas/Via Costeira" e dá outras providências. Natal: DOE/RN, 2001.

SILVA, Kelson de Oliveira. Políticas públicas e a promoção do turismo no Rio Grande do Norte. Disponível em: <http://www.mercator.ufc.br/index.php/mercator/303/273>. Acesso em: 08/08/2014.

SILVA, Heitor de Andrade. et al. Sistemas de espaços livres em Natal-RN: Zona de Proteção Ambiental como elementos estruturantes In: CAMPOS, Ana Cecilia Arruda; QUEIROGA, Eugenio Fernandes; GALENDER, Fany; DEGREAS, Helena Napoleon; AKAMINE, Rogério; MACEDO, Silvio Soares; CUSTÓDIO, Vanderli. Quadro dos Sistemas de Espaços Livres nas cidades brasileiras. São Paulo: FAUUSP, 2012. 